J. Lake Sci.(湖泊科学), 2009, 21(1): 94-100

http://www.jlakes.org. E-mail: jlakes@niglas.ac.cn

(C2009 by Journal of Lake Sciences

\title{
太湖自然渔业及其发展策略*
}

\author{
谷孝鸿 ${ }^{1}$, 朱松泉 ${ }^{1}$, 吴林坤 ${ }^{2}$, 曹 萍 $^{2}$, 白秀玲 ${ }^{1}$, 张 钰 $^{1}$, 何 俊 $^{1}$ \\ (1: 中国科学院南京地理与湖泊研究所, 南京 210008) \\ (2: 江苏省太湖渔业管理委员会, 苏州 215004)
}

摘 要: 渔业是太湖的主要功能之一, 它对改善水环境具有重要意义, 但又受制于环境的影响而变化. 从太湖渔业结构分析, 目前太湖自然渔业整体捕捞强度过大、资源破坏严重. 依据太湖多年渔获物捕捞结果，系统分析了太湖鱼类群落结构及其演 变动态. 通过对太湖不同生态区域渔获物产量和组成的分析, 研究了太湖自然渔业特征及存在问题, 提出了严格控制捕捞渔 具规格和捕捞强度、合理调整开捕时间、调整放流鱼种结构和比例, 合理发展湖泊渔业的思路. 同时, 依据太湖生物资源现状, 分析了太湖自然渔业潜力，提出太湖渔业发展要加强渔业环境建设、加强渔业对水环境改善功能的研究.

关键词: 太湖; 自然渔业; 渔获物; 群落结构

\section{The natural fishery and the development countermeasures in Lake Taihu}

\author{
GU Xiaohong ${ }^{1}$, ZHU Songquan ${ }^{1}$, WU Linkun ${ }^{2}$, CAO Ping ${ }^{2}$, BAI Xiuling ${ }^{1}$, ZHANG Yu $^{1} \&$ HE Jun \\ (1: Nanjing Institute of Geography and Limnlogy, Chinese Academy of Sciences, Najing 210008, P.R.China) \\ (2: Lake Taihu Fishery Management Commission of Jiangsu Pvovince, Suzhou 215004, P.R.China)
}

\begin{abstract}
Fishery is one of the main functions of Lake Taihu, which plays an important role in improving the water environment. However, it is also influenced to a large degree by the environmenal change. Recently, the main problems facing the natural fishery in Lake Taihu are the over-intensive catching and irrational utilization of natural resources. This paper, based on the data of many years' catches in Lake Taihu, analyzed the community structure of fishes in Lake Taihu and their succession dynamics. According to the fish yields and compositions in different area of Lake Taihu, the natural fishery characteristics and problems were studied. Some ideas were presented to develop the natural fishery based on the present research, such as controlling the fishing gear specifications and catching intensity, adjusting the catching time, regulating the structure and proportion of stocking fish species and developing lake fishery in a reasonable way. Meanwhile, the potential of natural fishery was analyzed on the basis of present biological resources in Lake Taihu. It suggested that the construction of fishery environment and studies on influence of fishery on water environment should be strengthened for the further development of lake fishery.
\end{abstract}

Keywords: Lake Taihu; natural fishery; catches; community structure

太湖地处长江三角洲南缘，气候温和、水系发达、水位稳定、湖底平坦、湖泊营养物质本底含量高、 水生生物种类丰富, 是典型的浅水富营养化湖泊, 具有发展湖泊渔业的良好环境. 在 1980 s 前太湖渔业主 要靠放流增养殖, 1982 年在太湖东太湖湾敞水区开展了网围养殖试验, 随着网围技术的完善网围养殖得 到不断发展, 1997 年网围养殖品种由草鳊鱼养殖为主转向河蟹养殖, 规模也不断扩大. 网围养殖的发展使 太湖渔业形式和结构发生了根本性的改变. 另外, 由于大面积的网围对水动力作用的改变导致的静水环 境及养殖对网围内植物的选择性和人工投饵等, 过量的网围养殖是东太湖水环境恶化最重要的促进者 ${ }^{[1]}$. 从太湖自然渔业结构分析，太湖渔业的主要问题是整体捕捞强度过大、资源破坏严重；一定区域内养殖

* 国家重点基础研究发展计划项目(2008CB418100)和江苏省自然科学基金(BK2007746)联合资助. 2007-04-04 收稿; 2008-08-12 收修改稿. 谷孝鸿, 男, 1966 年生, 博士, 研究员; E-mail: xhgu@niglas.ac.cn. 
面积过大、网围养殖布局和结构不合理; 湖泊水环境调控起重要作用的水生植被资源破坏和退化严重. 湖泊生物资源受到破坏，渔业发展的资源优势和潜力受到影响 ${ }^{[2-3]}$.

在我国长江流域分布着一系列大中小型浅水湖泊，由于经济的高速发展与资源的超强度开发，这些 湖泊都面临着与太湖相似的环境问题 ${ }^{[4-6]}$. 本文在对太湖过去渔业资料分析的同时, 结合 2003 年在太湖 布设采样点对渔业捕捞产量的统计分析, 研究了太湖渔业结构特征及其存在问题, 提出了调整和改善渔 业结构、合理发展湖泊渔业的建议，以期对太湖渔业发展有所促进.

\section{1 太湖自然渔业现状及其演变}

目前太湖自然渔业的生态类型主要包括鲤 (Cyprinus carpio)、鲫(Carassius auratus)、团头鲂 (Megalobrama mbilycephal)、鳊(Parabramis pekinensis)、鮊(Culter alburnus)、银鱼(Neosalanx taihuensis chen) 和梅鲚(Coilia ectenes taihuensis) 等定居性鱼类, 及青鱼(Myloparyngodon piceus)、草鱼(Ctenopharyngodon idelus)、鲢(Hypophthalmichthys molitrix)、鲟(Aristichthys nobilis)等主要靠人工放流补充种群数量的江河 半洄游鱼类 ${ }^{[7-8]}$. 这是太湖鱼类区系主要组成. 从历年统计资料分析, 1950-1980 年, 太湖天然渔业捕捞产量 持续上升, 年产量从不足 5000t 增长到 $15000 \mathrm{t}$ 以上, 2003 年达到 35453t, 单位水域产量达到 $146.03 \mathrm{~kg} / \mathrm{hm}^{2}$, 这在国内湖泊中较为少见(图 1).

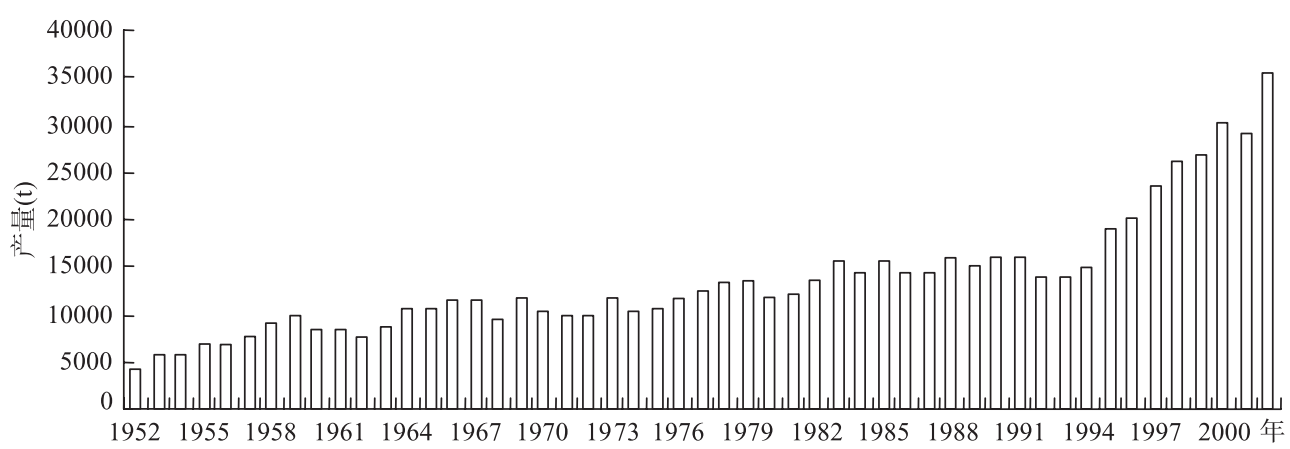

图 1 太湖天然渔业产量变动趋势

Fig.1 The changes of fish catch in Lake Taihu

比较太湖不同年份自然渔业结构, 太湖在 1950 年代渔业单位产量虽然不高, 但渔业结构相对合理. 从 1990 年代中期开始, 渔业产量有较大幅度上升(表 1), 特别是魰产量增加幅度较大, 而这一阶段起太 湖的富营养化也逐渐加重. 目前, 太湖天然渔业资源以鲚占绝对优势种群. 从鲚产量与太湖总氮平均含 量的年变化趋势看, 其具有较高相关性(图 2). 根据统计资料, 太湖渔业产量的不断增加与太湖营养水平 逐渐上升、饵料生物生产力持续增高具有一致性 ${ }^{[13]}$.

\section{2 太湖自然渔业特征分析}

\section{1 太湖自然渔业渔具特点}

太湖捕捞渔具随着不同作业时段有所变化. 目前太湖渔业捕捞主要采用大型拖网和网穊. 拖网是大 型的敞开式拉网, 规定在太湖 9 月 1 日开捕的一个月内使用, 主要用于捕捞鯑及银鱼. 网穊属迷陷类渔具, 又称迷魂阵. 网箱由网、旋和旋两端的取鱼部组成. 取鱼部有圈网式和囊网式两种, 太湖大多是囊网式, 便于船上操作, 其捕捞强度主要体现在墙网的长短和取鱼部网目的大小. 墙网越长和取鱼部网目越小, 捕捞强度越大，网䈤捕鱼对鱼的选择性小，能较好的反映湖泊鱼类资源状况.

太湖捕捞渔具总的趋势是向经久耐用、快捷、灵活机动的方向发展，捕捞强度普遍增大，因此控制 捕捞强度势在必行. 控制捕捞强度首先是规定禁渔期和禁渔区，在一定时间段和一定区域保护特定的鱼 类对象; 同时要根据捕捞对象, 规定合理的渔具渔法. 
表 1 太湖主要年份的捕捞总产量及其渔获物比例

Tab.1 The total yield and its composition of fish catches in Lake Taihu

\begin{tabular}{lllllll}
\hline & 1952 年 & 1963 年 & 1973 年 & 1983 年 & 1993 年 & 2003 年 \\
\hline 总产量 $(\mathrm{t})$ & 4063 & 8552 & 11564 & 15316 & 14072 & 35453 \\
鲚 & $15.8 \%$ & $55.2 \%$ & $57.4 \%$ & $46.2 \%$ & $24.8 \%$ & $55.7 \%$ \\
银鱼 & $12.9 \%$ & $4.1 \%$ & $8 \%$ & $5.6 \%$ & $12.5 \%$ & $2.1 \%$ \\
虾类 & $15.1 \%$ & $6.7 \%$ & $9.6 \%$ & $10 \%$ & $3.6 \%$ & $2.2 \%$ \\
鲢、鳙 & $15.7 \%$ & & $7.5 \%$ & $8.6 \%$ & & $3.4 \%$ \\
鲤、鲫 & $18.2 \%$ & & $7.8 \%$ & $6.5 \%$ & & $7.1 \%$ \\
青草鱼 & $2.8 \%$ & & $0.8 \%$ & $1.6 \%$ & & $0.9 \%$ \\
鮊鱼 & $5.5 \%$ & & $3.5 \%$ & $2.0 \%$ & $6.6 \%$ & $0.4 \%$ \\
其它 & $13.9 \%$ & & $5.5 \%$ & $19.6 \%$ & & $28.2 \%$ \\
平均产量 $\left(\mathrm{kg} / \mathrm{hm}^{2}\right)$ & 16.74 & 35.23 & 47.63 & 63.09 & 57.96 & 146.03 \\
\hline
\end{tabular}

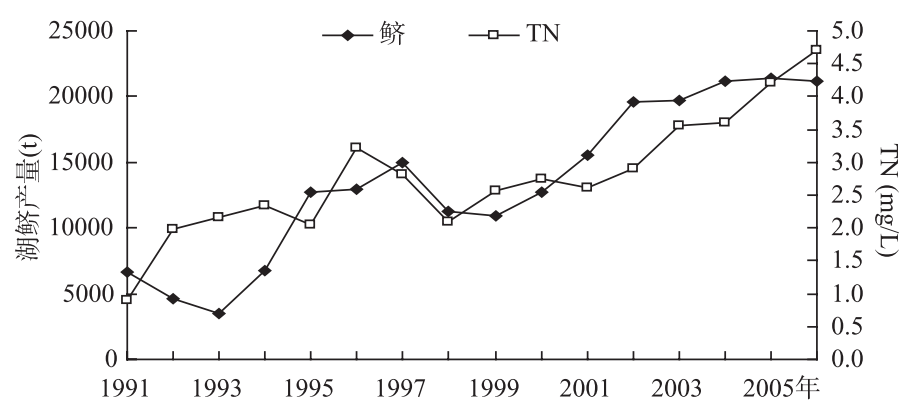

图 2 1991-2006 年太湖梅鲚与总氮变化

Fig.2 The changes of the coilia and TN in Lake Taihu from 1991 to 2006

\section{2 实验湖区选择和试验方法}

在太湖东部湖区和西部湖区各设置一大型定置网篓, 用于太湖渔获物的监测. 两座网箱规格一致, 网翼长 $200 \mathrm{~m}$, 网口宽 $10 \mathrm{~m}$, 网目 $20 \mathrm{~cm}$. 取鱼部网袋深 $3 \mathrm{~m}$, 口径 $50 \mathrm{~cm}$, 网袋网目 $2 \mathrm{~cm}$. 东部湖区网䈤(图 $\left.3 \mathrm{~A}: 120.33567^{\circ} \mathrm{E} 、 31.09903^{\circ} \mathrm{N}\right)$ 选择在苏州市东山、西山之间的常年繁殖保护区内, 偏东山岛, 北临余山 岛. 该区域生长有茂密的马来眼子菜、苦草等沉水植物. 常年风浪较小、底质肥沃. 西部湖区网䈤(图 3B: $\left.120.03182^{\circ} \mathrm{E} 、 31.27813^{\circ} \mathrm{N}\right)$ 设置在东氿出湖河流一城东港进太湖的河口附近，离河口约 $3 \mathrm{~km}$, 该区域无水 生植被分布. 两处网篓设置所在湖区代表了太湖有水生植被和无水生植被 2 种不同的生态类型.

\section{3 渔获物产量及主要特征}

2.3.1 试验网䈥的自然捕捞结果 实验监测的东部湖区和西部湖区网篓的渔获量分别是 $4216.7 \mathrm{~kg}$ 和 $8191.2 \mathrm{~kg}$ ，两网篓平均每座捕鱼 6204kg. 2003 年 9 月 1 日至 2004 年 1 月 10 日，太湖开捕期间进湖捕鱼的 正式网篓合计有 1100 座(渔业管理部门统一规定规格等), 推算出开捕期间网篓捕捞鱼产量为 $6824 \mathrm{t}$, 占当 年统计网䈤产量 7493t 的 91\%, 可见网䈤在太湖渔业捕捞使用中的普遍性和有效性.

2.3.2 试验区域渔获物的特征 (1)渔获物以鲤科鱼类为主体. 太湖东部、西部湖区捕获的鱼类共有 27 种(表 $2)$, 其中两区域捕捞共有种类 15 种，东部湖区自有种类 8 种，西部湖区自有种类 4 种. 东部湖区共捕获鱼类 
23 种, 鲤科鱼类占全部种类的 $83 \%$; 西部湖区 共有 19 种，鲤科鱼类占全部种类的 $68 \%$. 渔获 物重量组成中, 东部湖区以草鱼和鳊 (共占 $40.9 \%$ )、鲤(占 $19.2 \%$ )为主, 西部湖区以鲤(占 $49.77 \%$ )、鲫(占 $7.09 \%$ )为主. 东部湖区生长有 大型高等水生植物, 草食性鱼类分布比较集 中; 西部湖区大型底栖无脊椎动物分布及生 物量相对较高, 该区域底栖动物食性的鱼类 如鲤、鲫分布和捕捞产量较高, 反映出湖区鱼 类组成与环境特征相适应的特点. 另外, 对于 个体较小但具有重要经济价值的鱼类在各湖区 都占有一定比例, 东部湖区的赤眼鳟、拟刺鳊 鮈、尧嘴鲌、红鯺原鲌等约占 $15 \%$, 西部湖区的 黄颡鱼、红鳀原鲌、尧嘴鲌等约占 $14 \%$. 而在东 部湖区和西部湖区的起捕鱼中, 野杂鱼分别占 总量的 $13 \%$ 和 $15 \%$ 左右. 从实际监测的鱼类产 量和规格统计分析, 西部湖区平均日产量高于 东部湖区, 而东部湖区的捕捞鱼类总体规格要

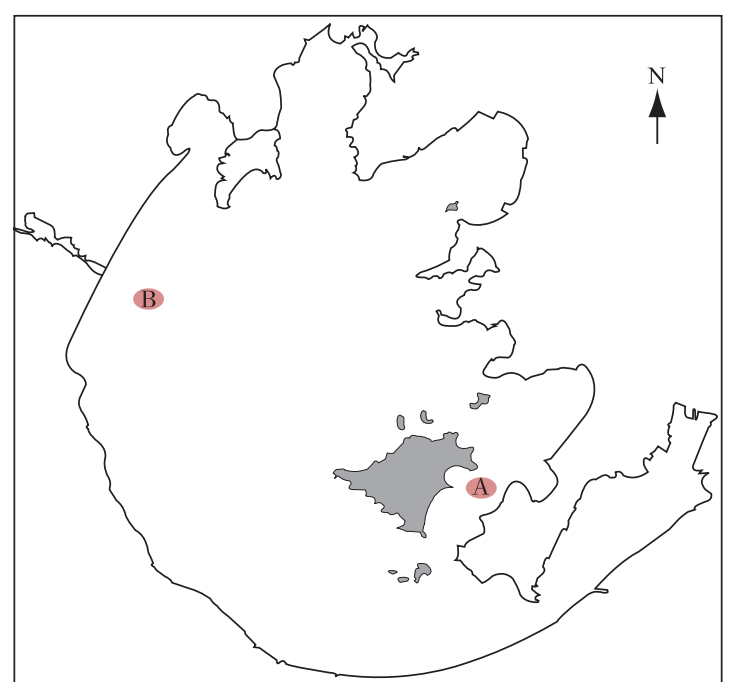

图 3 太湖不同湖区捕捞设置位置示意图

Fig. 3 The location of trap-net in different area of Lake Taihu 大于西部湖区.

表 2 太湖东部、西部湖区网簖渔获物种类

Tab.2 Fish species of catches by trap-net in different area of Lake Taihu

\begin{tabular}{|c|c|c|}
\hline 两湖区共有种类 & 东部湖区自有种 & 西部湖区自有种 \\
\hline 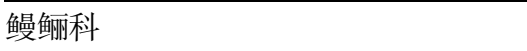 & 鲊科 & 鳀科 \\
\hline 鳗鲟 Anguilla japonica & 䲄 Siniperca chuatsi & 鲚 Coilia nasus \\
\hline 鲤科 & 鲤科 & 鲤科 \\
\hline 草鱼 Ctenopharyngodon idelus & 赤眼鳟 & 花鳃 \\
\hline 青鱼 Myloparyngodon piceus & Squaliobarbus curriculus & Hemibarbus maculates \\
\hline 红鯺原鲌 Cultrichthys erythropterus & 似鱎 & 鲿科 \\
\hline 尧嘴鲌 Culter alburnus & Toxabramis swinnonis & 瓦氏黄颡鱼 \\
\hline 蒙古红鲌 C. mongolicus & 团头鲂 & Pelteobagrus vachelli \\
\hline 餐 Hemiculter leucisculus & Megalobrama mbilycephal & 光泽黄颡鱼 \\
\hline 似鳊 Pseudobrama simony & 棒花鱼 & P. nitidus \\
\hline 大鯺鱊 Acheilognathus macropterus & Abbottina rivularis & \\
\hline 鲤 Cyprinus carpio & 黑鯺鳈 & \\
\hline 鲫 Carassius auratus & Sarcocheilichthys nigripinnis & \\
\hline 鲢 Hypophthalmichthys molitrix & 麦穗鱼 & \\
\hline 鳙 Aristichthys nobilis & Pseudorasbora parva & \\
\hline 鲿科 & 拟刺鳊鮈 & \\
\hline 黄颞鱼 Pelteobagrus fulvidraco & Paracanthobrama guichonoti & \\
\hline \multicolumn{3}{|l|}{ 鲇科 } \\
\hline 鲇 Silurus asotus & & \\
\hline
\end{tabular}

(2)太湖放流鱼类回捕率较高. 从网篓捕捞渔获物组成分析，由于太湖草鱼、鳙、鲢的产量完全依赖 放流鱼的数量, 因此, 依照网篓起捕的放流鱼类的平均体重及实际放流鱼数量和捕捞量, 可以推算出放 
流鱼类的回捕率(表 3). 从放流捕捞统计数据分析, 太湖放流鱼类回捕率相对较高, 这主要与高的捕拹强 度以及较长的捕捞时间有关.

表 3 太湖主要放流鱼类的回捕率

Tab.3 The situation of stocking and catch of main fish species in Lake Taihu

\begin{tabular}{ccccc}
\hline 鱼种 & 放流数量(尾) & 捕捞量 $(\mathrm{t})$ & 平均规格 $(\mathrm{g} /$ 尾) & 回捕率 $(\%)$ \\
\hline 草鱼 & 1646459 & 267.6 & 1564.9 & 9.8 \\
鲢 & 88800 & 493.55 & 919.4 & 21.3 \\
鳙 & 3266667 & 726 & 1218.8 & 18.2 \\
\hline
\end{tabular}

(3)小型鱼类及野杂鱼比例高. “野杂鱼” 通常是指个体较小及无市场价值的鱼类，如餐、大鳍䁤、 似鱎、麦穗鱼、黑鯺鳈、棒花鱼等. 太湖由于捕捞强度偏大，对每年捕捞产量的渔业结构进行分析，捕捞 产量中除野杂鱼外，小型鱼类如鲤、鲫、赤眼䲡、黄额鱼以及低龄的鲢、鳙等占有较高的比例. 东部湖 区的小型鱼类和 “野杂鱼” 占到总重量的 $35.35 \%$ ，西部湖区则占到 $38.88 \%$. 据多年的统计资料，太湖捕 捞群体中小型鱼类及野杂鱼一般占 $40 \%$, 可见在太湖两个区域设置的网箱, 其捕捞渔获物具有代表性, 可以初步反应出太湖捕捞渔业的结构特征.

\section{3 太湖自然渔业潜力及其调控}

目前魰和太湖短吻银鱼是太湖最主要的经济鱼类, 占渔获物 $60 \%$ 以上, 它们以浮游动物为食, 加上 鳙及大多数鱼类的幼鱼阶段也主要以浮游动物为食, 故对浮游动物形成巨大的捕食压力, 这与太湖蓝藻 水华暴发具有重要关联作用. 从“生物操纵” ${ }^{[9-10]}$ 和“营养级联动假说” ${ }^{[11-12]}$ 的食物链调控理论分析, 太湖 渔业结构如果做合理的调整和控制, 可对太湖富营养化水体起到调节作用, 达到 “以渔改水” 的目的.

\section{1 太湖渔业生产潜力}

太湖捕捞产量 1983 年为 $15316 t, 2003$ 年渔产量达 35453t, 是 1983 年产量的 2.31 倍. 1952-1960 年鲛 年产量在 640.5-4551.3t, 2003 年高达 19747.5t. 1983 年放流鱼占捕捞量的 $18.7 \%, 2003$ 年下降为 $10.14 \%$. 1980 年前太湖平均产量为 $45-52.5 \mathrm{~kg} / \mathrm{hm}^{2}$, 而那时水质处于 II 类水平. 目前, 由于人类活动的强烈干预, 水环境和渔业资源变化激励, 鲚种群扩张迅速, 太湖鱼类群落和种群趋于小型化. 而此时太湖水质平均 处于 IV - V 类水平. 理论上, 在通过凶猛性鱼类调控魰种群数量的基础上，可以通过放养适宜数量的鲢鲔 等来改善水体的浮游植物群落结构, 从而改善水质.

通过对太湖水域生物资源年均生物量(表 4)和现存量研究, 依据长江中下游地区浮游生物及其它底 栖与水生植被等饵料资源的 $\mathrm{P} / \mathrm{B}$ 系数(生物年生产总量与生物量比值)及利用率、饵料系数等 ${ }^{[20]}$, 参照国 内外湖泊生物生产力的统算方法 ${ }^{[21-22]}$, 推算出太湖合理放流的渔产潜力是浮游植物食性鱼产量为 $42.15 \mathrm{~kg} / \mathrm{hm}^{2}$ 、底栖动物食性鱼产量为 $24.45 \mathrm{~kg} / \mathrm{hm}^{2}$ 、高等植物食性鱼产量为 $26.26 \mathrm{~kg} / \mathrm{hm}^{2}$ 、有机碎屑食性 鱼产量为 $21.07 \mathrm{~kg} / \mathrm{hm}^{2}$.

表 42003 年太湖生物资源年均生物量

Tab.4 The average biomass of biology resource in Lake Taihu in 2003

\begin{tabular}{ccccc}
\hline 类别 & 浮游植物 $(\mathrm{mg} / \mathrm{L})$ & 浮游动物 $(\mathrm{mg} / \mathrm{L})$ & 底栖动物 $\left(\mathrm{g} / \mathrm{m}^{2}\right)$ & 水生高等植物 $\left(\mathrm{g} / \mathrm{m}^{2}\right)$ \\
\hline 年均生物量 & 4.151 & 3.154 & $44.50+1.47$ & 2500 \\
P/B 系数 & 60 & 25 & $10(15)$ & 1.2 \\
利用率 & $20 \%$ & $25 \%$ & $25 \%^{*}(40 \%)^{* *}$ & $30 \%$ \\
饵料系数 & 40 & 20 & $60^{*}(15)^{* *}$ & 120 \\
\hline
\end{tabular}

$*$ 底栖动物中腹足类与瓣鳃类利用率与饵料系数; $* *$ 底栖动物中摇蚊及其它塞毛类等利用率与饵料系数.

综上饵料生物的估算，太湖近年的渔业生产能力为 $113.93 \mathrm{~kg} / \mathrm{hm}^{2}$, 即太湖年捕捞渔业产量应该控制 
在 28000t 左右. 而目前的捕捞产量达到 $36000 \mathrm{t}$ (不包括未统计到数据), 因此必须在捕捞方式和手段上有 强制规定，这样才能给湖泊渔业提供休养生息的机会，渔业才能真正做到可持续发展.

\section{2 太湖自然渔业的可持续发展及对水环境的调控}

3.2.1 严格控制网筙规格和捕捞强度 湖泊主要经济鱼类(特别是鲤科鱼类)的产量, 完全依赖放流鱼种的 数量和质量. 根据生态学和经济学最佳原则, 放养鱼类最佳捕捞规格应该是在该规格起捕后出售价值与 成本加开支相等的那个节点上. $W=C N /(P \times n)=C /(D \times P), W$ 为最小起捕规格, $C N$ 为总成本, $N$ 为投放鱼种 数, $n$ 为回捕尾数, $C$ 为总成本/投放鱼种数, $D$ 为回捕率 $(n / N), P$ 为鱼的市场价格. 放养鱼类的最小捕捞规 格是随着鱼类放养总成本的增加而增高, 随着放养鱼种成活率提高而降低的参数. 理论上, 鱼类最小捕 捞规格并非最佳规格，以经济学角度看，前者只能是收支平衡，后者则代表最高渔业产值利润.网篓起 捕的放流鱼中, 要根据放流鱼捕捞时可达到商品鱼标准而确定网䈤取鱼部网目大小. 网目大小与起捕鱼 的最大周长相关，因各种鱼的体型不同，所以网目大小确定应根据主要产量鱼类规格而定.

太湖自然渔业产量 $60 \%$ 以上是由鲚、银鱼组成. 银鱼是生理成熟一年而繁殖死亡，而魰一龄鱼也占 $98 \%{ }^{[13]}$. 捕捞强度的控制关键是对捕捞时间、捕捞区域及网篓墙网长度和取鱼部数量及其网目大小的控制. 在太湖渔业中，捕捞渔获物个体偏小、“野杂鱼” 比例过高、优质鱼类资源枯竭等，主要是放流鱼类的起捕 规格偏小. 2003 年对太湖捕捞鱼类种群的监测显示，除草鱼能超过 $500 \mathrm{~g}$ 外，其它如鲢、鳙、团头鲂(鳊)因当 年放流鱼种规格大小不一，9 月起捕时，不少个体尾重仍不足 $250 \mathrm{~g}$, 甚至只有 50- $100 \mathrm{~g}$. 这一规格鱼如在湖 中继续生长, 就会形成很大的资源优势而增加渔产量. 而不控制捕捞强度, 每年花费大量人力财力向湖中 放流的大批鱼种, 又成为当年渔获物, 造成浪费并对资源产生严重破坏.

3.2.2 调整太湖的休湖时间 太湖的捕捞时间是每年 9 月 1 日至翌年的 1 月 15 日. 9 月气温、水温仍较高, 是鱼类最适宜的生长期. 同时, 9 月过高的气温对捕捞渔获物保鲜不利. 根据 2003 年的放流试验，在苏州 湖区测定的放流草鱼、团头鲂、鲤、鲢、鳙等 10 月捕捞时的平均体重比 9 月的要高 5\%-33\%. 因此，从 湖泊鱼类有效生长角度，建议开捕时间延迟一个月至 10 月 1 日。

根据 2003 年捕捞试验逐日统计, 开捕第一个月产量最高. 西部湖区监测点 9 月 2 日至 30 日 29d 产量是 整个捕捞期间产量的 $55 \%$, 东部湖区同期为 $50 \%$. 湖泊渔业的自然捕捞产量主要在开捕的第一个月, 而后 所有捕捞时间的总产量常常低于开捕第一月的产量. 可见，湖泊渔业产量不完全决定于捕捞时间的长短， 而是依赖于湖中资源量. 开捕时间后延一个月，对于提高鱼产量，保护鱼类资源，减轻渔民劳动强度，加强 湖区管理等是有益的. 因此，针对目前太湖渔业资源的特点及实际捕捞时间与渔获量的关系，建议延长太 湖渔业的休湖时间，每年控制捕捞时间在 4 个月，休湖自 2 月 1 日至 9 月 30 日.

3.2.3 合理调整放流鱼种结构和比例 太湖捕捞渔业主要依靠放流鱼种补给, 这是稳定太湖渔产量的重要 措施 ${ }^{[14-15]}$. 太湖曾有记录 103 种鱼，据近年调查已不足 60 种 ${ }^{[16]} .2003$ 年网篓起捕鱼仅见到 27 种. 理论上, 湖中原有鱼类的生态位大量空缺, 为放流鱼类提供良好的生态条件 ${ }^{[17]}$.

太湖鱼类的放流补给，首先要坚持原有鱼类区系作为放流对象.放流种类以 “四大家鱼”为主，同时 补充一些在太湖能自然繁殖的鲤、鲌和团头鲂等. 其次, 要坚持放流适宜规格和合理的鱼种数量. 渔产量 决定于捕捞出的个体平均重量与个体数量, 从多年的统计监测分析, 通常是放流规格越大, 回捕率越高, 但相应成本也越大. 第三，同一种放流鱼种的规格不宜相差太悬殊，在捕捞强度未得到控制时，放流个 体较小的鱼种由于生长的原因，其放流后又不断地被捕出，提高了放流成本. 第四，放流一定的大型凶 猛肉食性鱼类, 以调节太湖不合理的鱼类种群. 目前, 太湖渔业中低值的以浮游动物为主要食性的鲚占 $60 \%$ 以, 从改善水环境的上行效应出发, 太湖需要通过低值鱼类的转化, 在调控渔业结构和水质、提高 湖泊生态系统的生物多样性的同时，实现食物链的优化和渔产品附加值的提高.

\section{3 太湖渔业发展的目标}

我国内陆水体的战略目标是：“保护水质，兼顾渔业，适度开发，持续利用”。资源开发必须 “适度”， 对于渔业而言，应该做到捕捞不影响鱼类群落和种群结构的稳定，人工放流不影响生态系统的稳定. 太 湖渔业生产潜力以保护水质和持续利用为前提，在饵料资源消耗相同状态下，要不断调整人工放流种群 结构, 不断提高渔业产值. 
太湖渔业是太湖综合功能的重要方面. 为实现太湖渔业的可持续发展，需加强渔业环境建设. 首先， 要采取种植和保护相结合，改造太湖退化的水生植被，恢复物种多样性，维持湖泊生态系统的稳定. 其 次, 要合理布局太湖养殖渔业区, 种养殖配套, 构建渔业高效利用的自净生态系统. 第三, 要严格控制捕 捞强度, 加大湖泊人工放流，同时要严格控制草食性的草鱼和团头鲂等放流鱼种数量，防止掠食而对沉 水植物生长的影响. 第四, 要积极发展鱼类食品加工业与渔业有关的延伸产业, 以便转移湖区渔业劳力 和增加渔产品的附加值.

\section{4 小结}

太湖的鱼类区系是冲积平原常见的种属. 目前鱼类种群组成是小型定居型鱼类比例明显增长，而大 中型的半洄游性和定居型鱼类比例下降. 特别是在近年的渔获物中, 鲚所占比例高达整个渔获物的 $60 \%$ 以上, 其渔获物结构及其浮游动物的食性, 是导致太湖水体浮游植物生物量增高, 水体富营养化的主要 原因之一. 太湖渔业的发展，必须严格控制捕捞强度，要在强化天然渔业资源繁殖保护的前提和基础上 大力实施滤食性鱼类、有机碎屑食性鱼类的放养，同时要适当提高高营养级鱼类的放流比例，通过食物 链关系, 达到控制浮游动物食性的鱼类, 从而实现湖泊湖泊富营养化的生物调控. 要根据鱼类生长节律, 合理调整不同鱼类的捕捞强度和时间，维持湖泊鱼类的资源再生量.

\section{5 参考文献}

[1] 谷孝鸿, 胡维平, 胡耀辉等. 人类活动对浅水湖泊的影响——以东太湖为例. 河海大学学报(自然科学版), 2004, 32(7): $142-146$.

[2] 刘恩生, 刘正文, 陈伟民等. 太湖鱼类产量、组成的变动规律及与环境的关系. 湖泊科学, 2005, 17(3): 251-255.

[3] 谷孝鸿, 白秀玲, 江 南等. 太湖渔业发展及区域设置与功能定位研究. 生态学报, 2006, 26(7): 2247-2254.

[4] 王友亮. 长荡湖网围养殖有效利用面积研究. 河海大学学报, 1991, (18): 175-183.

[5] 朱清顺. 江苏湖泊鱼类资源现状及其湖泊渔业. 水产养殖, 1992, (6): 23-26.

[6] 朱成德, 王玉纲, 余 宁. 滆湖渔业高产模式及生态渔业研究文集. 北京: 中国农业出版社, 1997.

[7] 朱成德. 太湖水产资源的合理利用与增殖途径的初步探讨. 江苏农业科学, 1980, 6: 50-53.

[8] Li Kangmin. Management and restoration of fish communitiues in Lake Taihu, China. Fisheries Management and Ecology, 1996, 6: 71-81.

[9] Carpenter SR, Krtchell JF, Hodgson JR et al. Regulation of lake primary productivity by food web structure. Ecology, 1987, 68: 1863-1876.

[10] 陈少莲. 鲢、鳙在东湖生态系统的氮、磷循环中的作用. 水生生物学报, 1991, 15: 8-26.

[11] Lazzaro X, Drenner RW, Stein RA et al. Planktivores and plankton dynamics: effects of fish biomass and planktivore type. Can J Fiash Aquat Sci, 1992, 49: 1466-1473.

[12] Andersson G, Berggren H, Cronberg G et al. Effects of planktivorous and benthivorous fish on organisms and water chemistry in eutrophic lakes. Hydrobiologia, 1978, 59: 9-15.

[13] 刘恩生, 许建新, 程建新等. 太湖湖魰渔获量变化与主要鱼类渔获量间关系的多元分析. 安徽农业科学, 2005, 33(9): 1657-1659.

[14] 朱成德，钟瑄世. 太湖人工放流效果的初步探讨. 淡水渔业, 1984, 5: 2-9.

[15] 顾良伟. 太湖人工放流的初步探讨. 水产学报, 1986, 10(2): 223-228.

[16] 朱松泉. 2002-2003 年太湖鱼类学调查. 湖泊科学, 2004, 16(2): 121-123.

[17] 蔡仁達. 太湖水产资源调查及其增殖途径探讨. 古今农业, 1987, 1: 125-133.

[18] 孙顺才, 黄渏平. 太湖. 北京: 海洋出版社, 1993.

[19] 秦伯强, 胡维平, 陈伟民. 太湖水环境演化过程与机理. 北京: 科学出版社, 2004

[20] 何志辉. 淡水生物学(下册). 北京: 农业出版社, 1985.

[21] 何志辉. 浮游生物和淡水渔业. 淡水渔业, 1982, (4): 28-30.

[22] Carpenter SR, Kitchell JF. Consumer control of lake productivity. Bioscience, 1988, 38: 764-769. 